\title{
Effect of Preemptive Episiotomy in Prevention of Perineal Tears in Multiparous Women with High Striae Gravidarum Score: A Randomized Controlled Study
}

\author{
Ahmed M Abbas ${ }^{1 *}$, Fatma M Kamel ${ }^{2}$ and Safwat A Salman ${ }^{1}$ \\ ${ }^{1}$ Department of Obstetrics \& Gynecology, Faculty of Medicine, Assiut University, Egypt \\ ${ }^{2}$ Department of Obstetrics \& Gynecology, Abnoub Central Hospital, Assiut, Egypt.
}

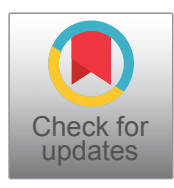

\begin{abstract}
Objective: To evaluate the effect of preemptive episiotomy in the prevention of perineal tears (PT) in multiparous women with high striae gravidarum (SG) score.

Methods: A randomized controlled study (Clinical Trials.Gov: NCT02717676) included multiparous women with singleton full-term pregnancy. SG score was assessed according to Atwal score at four body sites (Abdomen, breast, buttocks, hips). Women with total score $>12$ were randomized to Group $(A)$ : episiotomy was done after crowning of the fetal head during the second stage of labour and Group (B): no episiotomy was done. The primary outcome was the rate of third and fourth degree perineal tears.

Results: Two-hundred fifty women were included in the study (125 in each arm). The overall incidence of PT was significantly high in group (B) than group (A) $(90.4 \%$ Vs. $23.5 \%$ respectively, $p<0.001)$. In addition, the incidence of third and fourth-degree perineal tears was significantly higher in group (B) (15\% Vs. 3.3\%, $p=0001)$. Similarly, the incidence of first and second-degree perineal tears was significantly higher in group (B) $(75.4 \%$ vs. $20.2 \%, p=0.001)$ than group (A).

Conclusion: Preemptive episiotomy in multiparous women with high SG score seems to be an effective strategy in prevention of perineal tears during vaginal delivery, especially the third and fourth-degree tears.
\end{abstract}

Keywords

Striae gravidarum, Episiotomy, Perineal tears, Vaginal delivery

\section{Introduction}

Perineal trauma defined as any type of damage to the female genitalia during delivery, either spontaneously or iatrogenically by episiotomy or instrumental delivery [1]. Anterior perineal trauma involves the anterior vaginal wall, urethra, clitoris and labia. Posterior perineal trauma involves the posterior vaginal wall, perineal muscle, perineal body, anal sphincters, anal canal and rectal mucosa [1]. Most of perineal tears (PT) occurring during vaginal delivery affects the posterior vaginal wall, extending towards the anus [2]. PT can affect up to $90 \%$ of women who undergo vaginal delivery. This incidence decreases with subsequent deliveries to $68.8 \%$ in multiparous women [3].

Primiparity is considered the most important risk factor for spontaneous PT [4]. However; certain factors could increase the risk of $\mathrm{PT}$ even in multiparous women as increased maternal weight gain during pregnancy, prolonged pregnancies, short perineal length, previous scarred perineum, and the appearance of striae gravidarum (SG) during pregnancy [5-
8]. Preemptive episiotomy as an intervention to avoid PT is controversial; therefore, prediction of women at risk for PT is better to improve the vaginal delivery outcomes [9].

SG is a common skin change observed during pregnancy that affects between $55 \%$ and $90 \%$ of women [10]. SG presents as atrophic linear scars and can cause distress, often leading to a decrease in quality of life [11]. Scoring of SG

*Corresponding author: Dr. Ahmed M Abbas, MD, Department of Obstetrics and Gynecology, Assiut University, Egypt, Women Health Hospital, Assiut Egypt, 71511, Tel: +208-8241-4616, Fax: +208-8920-2503.

Accepted: December 11, 2021

Published online: December 13, 2021

Citation: Abbas AM, Kamel FM, Salman SA, et al. (2021) Effect of Preemptive Episiotomy in Prevention of Perineal Tears in Multiparous Women with High Striae Gravidarum Score: A Randomized Controlled Study. Annals Gynecol Obstet 5(1):142-146 
Citation: Abbas AM, Kamel FM, Salman SA, et al. (2021) Effect of Preemptive Episiotomy in Prevention of Perineal Tears in Multiparous Women with High Striae Gravidarum Score: A Randomized Controlled Study. Annals Gynecol Obstet 5(1):142-146

severity was available using Atwal scoring system [12]. This score provides a rank based on observation of four common sites of SG (abdomen, hips, buttocks, and breast). The final score for each body site ranges from 0 to 6 based on the number and color of SG. The total striae score (TSS) ranges from 0 to 24 . Women having TSS score $\leq 12$ indicated mild striae, TSS score (13-18) indicated moderate striae and TSS > 18 indicated severe striae [12].

Previous studies concluded that SG assessment appears to predict the occurrence of PT and they recommend training the health personnel to calculate the TSS that can help them to decide if episiotomy need to be performed not $[8,13]$. Episiotomy definitely seems to be preventive for PT, but giving episiotomy for the same is still debatable as episiotomy itself is associated with perineal complications.

Our hypothesis is performing episiotomy in women with high TSS could protects against occurrence of PT. Therefore, the aim of the current study is to evaluate the value of preemptive episiotomy for prevention of PT in multiparous women with high SG score.

\section{Patients and Methods}

The current study was a registered open-labeled randomized clinical trial (clinical trial.gov: NCT02717676) carried out in a tertiary University hospital between March 2016 and June 2018. The study protocol was approved by The Institutional ethical review board. We obtained awritten consent from all participants after discussing the nature of the study.

\section{Eligible participants}

We invited all multiparous women attended the reception unit of the hospital to be enrolled in the study if they met our inclusion criteria. We included women aged $18-40$ years, with singleton pregnancy, spontaneous onset of labor, average-sized fetus (2500-4000gm), cephalic presentation and the gestational age 37-40 weeks. Women with previous cesarean sections, multiple pregnancy, preterm labor, malpresentation, suspected fetal macrosomia, and medical disorders as diabetes or hypertension were excluded.

\section{Recruitment}

A detailed history was taken from all women included age, parity, gestational age, previous miscarriages, previous episiotomy, gestational weight gain and Body mass index (BMI) was calculated for each participant.

\section{Intervention}

Inspection of the four body areas described in the Atwal SG score (abdomen, hips, buttocks, and breast) was done and the TSS was calculated for each woman [12]. The score includes the following criteria (a) the number of SG at each body site ( $0=$ no striae signs, $1=1-4$ striae, $2=5-10$ striae, $3=$ more than 10 striae) and (b) the color of the SG which ranges from pale to purple ( $0=$ no redness, $1=$ pink, $2=$ dark red, $3=$ purple). The final score for each body site, relating to number and color, ranges from 0 to 6 . Accordingly, the TSS ranges from 0 to 24 . Women having TSS score up to 12 were considered to be having mild
SG, TSS score (13-18) indicated moderate SG and TSS more than 18 were considered to be having severe SG.

Women with moderate or severe SG (TSS >12) are considered to have high TSS. They were randomized to:

Group (A): episiotomy was done after the crowning of fetal head during the second stage of labour and,

\section{Group (B): no episiotomy was done}

All study participants were followed until the second stage of labor using the partogram. All women were delivered by the same obstetrician. Mediolateral episiotomy was done after crowning of the fetal head then slow assisted delivery of the head with perineal support was the method of delivery. Examination of the birth canal after delivery of the placenta with the active method was done. Any perineal tear was documented as regards the degree, location, number and length. The length of perineal tear was measured by a metal graduated and sterilized ruler. Presence of any other vaginal or cervical tears was recorded.

\section{Randomization}

A statistician prepared a computer-generated random table and placed the allocation data in serially numbered closed opaque envelopes. Each envelope had a card noting the intervention inside either group (A) or (B). Allocation was unchanged after opening the closed envelopes. Neither the women nor the investigators could be blinded to the purpose of the study.

\section{Sample size}

To test our hypothesis, based on the result of previous study, the incidence of perineal tears in women with high TSS $>12$ was $63.3 \%$. We supposed that episiotomy could reduce the rate of PT by $50 \%$. Using a two-sided chi-square $(\chi 2)$ test with an $\alpha$ error of 0.05 , a total sample size was calculated to be 226 patients in both groups (113 in each arm) with $80 \%$ power to detect a $50 \%$ difference (Epi-info ${ }^{\mathrm{TM}}$, Centers for Disease Control and Prevention, USA). Assuming a rate of loss to follow-up of $10 \%, 250$ women were included in the study.

\section{Study outcomes}

The primary outcome was the difference in the rate of $3^{\text {rd }}$ and $4^{\text {th }}$ degree PT between both groups. The secondary outcomes included the rate of $1^{\text {st }}$ and $2^{\text {nd }}$ degree perineal tears, number and length of perineal tears, the rate of paraurethral, vaginal and cervical tears in both groups.

\section{Statistical analysis}

The collected data were analyzed using IBM Statistical Package for Social Sciences software (SPSS), $21^{\text {st }}$ edition. Continuous data were expressed as mean \pm standard deviation and categorical data as frequencies and percentages. When data were tested for normality by Kolmogorov-Smirnov test, they were normally distributed. Therefore, independent t-test and Chi-square (x2) test were used to compare the outcomes in both groups. Results were considered statistically significant at a p-value $<0.05$. 
Citation: Abbas AM, Kamel FM, Salman SA, et al. (2021) Effect of Preemptive Episiotomy in Prevention of Perineal Tears in Multiparous Women with High Striae Gravidarum Score: A Randomized Controlled Study. Annals Gynecol Obstet 5(1):142-146

\section{Results}

Three hundred eighty-three women were approached to participate in the study during the study period. We excluded 28 women as they did not meet the inclusion criteria. Moreover, 105 women were found to have low TSS $\leq 12$. The remaining 250 women were randomized into the two study groups; group (A) with episiotomy and group (B) without episiotomy (125 women in each arm). Six women in group (A) and 11 women in group (B) were excluded from the final analysis as they did not deliver vaginally. Therefore, 119 women in group (A) and 114 women in group (B) were finally analyzed (Figure 1: The study flowchart).

Table 1 shows that both groups were similar regarding the baseline characteristics ( $p>0.05$ ). No statistical significant difference between both groups regarding the TSS and the individual scores at each body site. Moreover, no difference between both groups regarding the duration of second stage of labor $(p=0.121)$ and the neonatal birth weight $(p=0.827)$.
Regarding the study outcomes, Table 2 shows that the overall incidence of PT was significantly higher in women delivered without episiotomy than episiotomy group $(90.4 \%$ Vs. $23.5 \%$ respectively, $p<0.001)$. In addition, the incidence of the four degrees of PT was significantly higher in the same group. No statistical difference between both groups regarding the incidence of para-urethral, vaginal and cervical tears ( $p=0.127,0.294$ and 0.164 respectively). Also, no difference in the incidence of multiple tears $(p=0.742)$ and the length of tears between both groups $(p=0.284)$.

\section{Discussion}

In the current study, preemptive episiotomy in multiparous women with high SG score is associated with decreased rate of perineal tears.

SG are stretch marks that could be present in different sites of pregnant women bodies. They are indicative of poor skin elasticity [13]. Similarly, poor elastic tissue is more liable

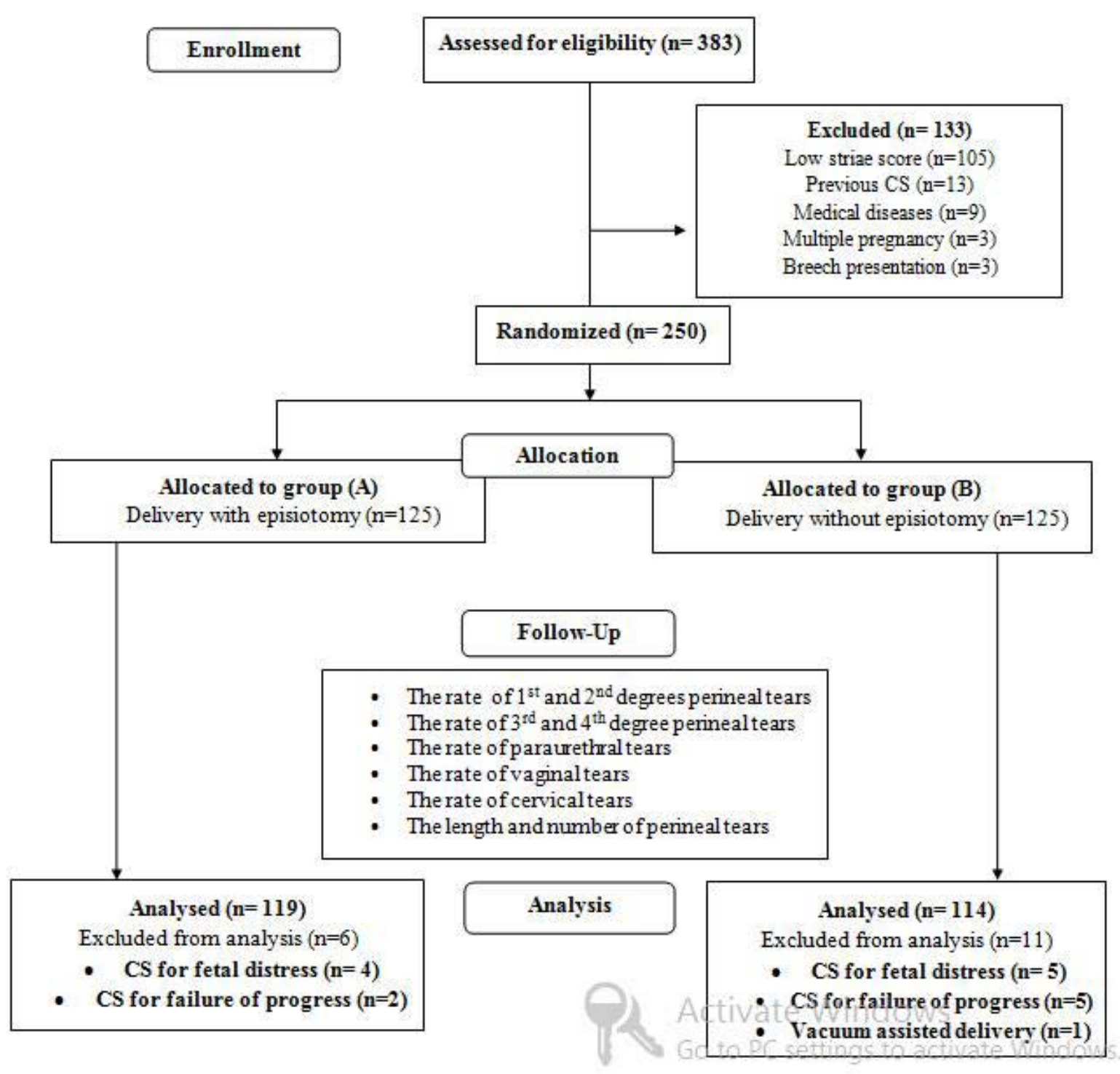

Figure 1: The study flowchart. 
Citation: Abbas AM, Kamel FM, Salman SA, et al. (2021) Effect of Preemptive Episiotomy in Prevention of Perineal Tears in Multiparous Women with High Striae Gravidarum Score: A Randomized Controlled Study. Annals Gynecol Obstet 5(1):142-146

Table 1: The baseline characteristics and the striae scores of the study groups.

\begin{tabular}{|l|c|c|c|}
\hline \multirow{2}{*}{ Characteristics } & Group A: Episiotomy & Group B: No Episiotomy & P-value \\
\cline { 2 - 4 } & $(\mathbf{n = 1 1 9 )}$ & $25.77 \pm 3.73$ & 0.344 \\
\hline Age (years) & $25.11 \pm 3.72$ & $3.0 \pm 1.81$ & 0.231 \\
\hline Parity & $2.91 \pm 0.96$ & $38.92 \pm 1.45$ & 0.882 \\
\hline Gestational age (weeks) & $38.97 \pm 1.12$ & $2.6 .4 \pm 3.07$ & 0.084 \\
\hline Gestational weight gain (Kg) & $26.33 \pm 2.59$ & $9.77 \pm 2.63$ & 0.733 \\
\hline Previous miscarriages, n (\%) & $9.38 \pm 2.69$ & $26(22.8)$ & 0.34 \\
\hline Previous episiotomy, $\mathbf{n}(\mathbf{\%})$ & $22(18.5)$ & $61(53.5)$ & 0.139 \\
\hline Duration of second stage (min) & $55(46.2)$ & $5.32 \pm 1.47$ & 0.121 \\
\hline Neonatal birth weight (Kg) & $5.09 \pm 0.69$ & $2.91 \pm 0.28$ & 0.827 \\
\hline Breast score & $2.89 \pm 0.27$ & $3.78 \pm 1.33$ & 0.157 \\
\hline Buttocks score & $3.84 \pm 1.43$ & $4.73 \pm 1.51$ & 0.277 \\
\hline Hips score & $4.61 \pm 1.51$ & $3.57 \pm 1.49$ & 0.144 \\
\hline Abdomen score & $3.84 \pm 1.31$ & $5.89 \pm 0.45$ & 0.119 \\
\hline TSS & $5.79 \pm 0.56$ & $18.06 \pm 2.15$ & 0.31 \\
\hline
\end{tabular}

TSS; total striae score

All data are presented as mean \pm standard deviation

\#Data are presented as frequency (\%)

Table 2: The primary and secondary outcomes of women of the study groups.

\begin{tabular}{|l|c|c|c|}
\hline \multirow{2}{*}{ Outcomes } & Group A: Episiotomy & Group B: No episiotomy & \multirow{2}{*|}{ P-value } \\
\cline { 2 - 4 } & $(\mathbf{n = 1 1 9 )}$ & $(\mathbf{n = 1 1 4})$ & $\mathbf{< 0 . 0 0 1}^{*}$ \\
\hline Perineal tears & $28(23.5)$ & $103(90.4)$ & $\mathbf{0 . 0 0 1}^{*}$ \\
\hline $\mathbf{1}^{\text {st }}$ degree perineal tears & $15(12.6)$ & $55(48.2)$ & $\mathbf{0 . 0 0 4}^{*}$ \\
\hline $\mathbf{3}^{\text {rd }}$ degree perineal tears & $9(7.6)$ & $31(27.2)$ & $\mathbf{0 . 0 0 1}^{*}$ \\
\hline $\mathbf{4}^{\text {th }}$ degree perineal tears & 0 & $9(7.9)$ & $\mathbf{0 . 0 0 1}^{*}$ \\
\hline Para-urethral tears & $4(3.3)$ & $8(7.1)$ & 0.127 \\
\hline Vaginal tears & $3(2.5)$ & $6(5.2)$ & 0.294 \\
\hline Cervical tears & $3(2.5)$ & $4(3.5)$ & 0.164 \\
\hline Length of perineal tears(cm) & $2(1.7)$ & $6(5.2)$ & 0.284 \\
\hline Multiple perineal tears & $3.96 \pm 0.95$ & $4.27 \pm 1.46$ & 0.742 \\
\hline
\end{tabular}

SG; striae gravidarum, TSS; total striae score, *Statistical significant difference

All data are presented as number (\%)

\# Variables are presented as mean \pm standard deviation

to tear if stretched as the perineal and vaginal tissue during labor [8]. Therefore, women with severe SG are likely to have more PT during vaginal delivery. Till now, the use of liberal episiotomy to prevent PT is questionable. Previous studies reported that morbidity is higher in women who deliver with episiotomy that in those without one. Therefore, any predictors that can help to determine who can deliver without an episiotomy should be thoroughly investigated.

In the present study, we found significant reduction in the rate of PT in women delivered with episiotomy than those who delivered without episiotomy (23.5\% Vs. $90.4 \%$ respectively, $\mathrm{p}<0.001$ ). Moreover, the rate of $3^{\text {rd }}$ and $4^{\text {th }}$ degree PT (Obstetric anal sphincter injuries [OASIS]) was significantly lower when episiotomy performed to those women $(p=0.001)$. Similarly, previous observational study by Wahman, et al., 2000 included 82 women with moderate/ severe SG reported higher rate of PT in women delivered without episiotomy than those delivered with episiotomy (60.0\% Vs. 21.2\%) [14]. Their findings are in agreement with our results. Accordingly, they conclude that women with SG are at higher risk for PT at vaginal delivery and obstetricians should restrict the use of episiotomy in women with no abdominal striae. We agree with their conclusions through the obtained results from our study.

Another study matched with our results by Kapadia, et al., 2014 evaluated a cohort of 166 Indian women with TSS >12 and found significantly lower rate of PT in women delivered with episiotomy versus those who delivered without episiotomy (19.2\% Vs. 83.3\% respectively, $p=0.001$ ) [13].

In 2019, Banu and his colleagues assessed SG score in 189 women who delivered vaginally [14]. They found that women with moderate and severe SG who were given episiotomy had significantly less PT than those who were not given episiotomy ( $8.5 \%$ Vs. $27.5 \%$ and $0.5 \%$ Vs. $6.9 \%$, respectively, $p<0.01$ ). Our results agree with them and this suggests that women who were given episiotomy were less likely to develop PT in most of cases. Therefore, episiotomy has some protective effect against PT.

Additionally, our results coincide with Patel, et al., 2019 who reported in their cross sectional study on 394 women that PT occurred in two women out of 32 women delivered 
with episiotomy (6.25\%), while PT were present in 117 women out of 362 women who delivered without episiotomy (32.3\%) with statistical significant difference $(p<0.01)$. Moreover, in women with high TSS, perineal tears were present in two out of seven women delivered with episiotomy $(28.6 \%)$ versus 88 out of 134 women (65.7\%) delivered without episiotomy. This shows that women who had an episiotomy were less likely to have PT especially in those with high SG score.

To our knowledge, this is the first study evaluating the value of preemptive episiotomy in multiparous women with high SG score. The strengths of the present study were the random assignment of the participants to the study groups and the relatively large sample size of included women.

\section{Conclusion}

In conclusion, preemptive episiotomy in multiparous women with high SG score seems to be an effective method in decreasing the rate of perineal tears during vaginal delivery. Further trials to evaluate the effect of perineal massage and pelvic floor exercises before delivery for prevention of perineal tears in women with high SG score are recommended.

\section{Funding}

No funding received for this research

\section{Conflict of interest}

The authors declare that they have no conflict of interest.

\section{References}

1. Goh R, Goh D, Ellepola H (2018) Perineal tears-A review. Aust J Gen Pract 47: 35-38.

2. Howells IE, Abasi IJ (2018) Genital tract lacerations in women delivered by medical doctors at the Niger Delta university teaching hospital, Southern Nigeria. Asian Research Journal of Gynaecology and Obstetrics 1: 1-10.
3. Smith LA, Price N, Simonite V, et al. (2013) Incidence of and risk factors for perineal trauma: A prospective observational study. BMC pregnancy and childbirth 13: 59.

4. Groutz A, Hasson J, Wengier A, et al. (2011) Third- and fourthdegree perineal tears: Prevalence and risk factors in the third millennium. Am J Obstet Gynecol 204: 347.

5. Albers LL, Greulich B, Peralta P (2006) Body mass index, midwifery intrapartum care, and childbirth lacerations. J Midwifery Womens Health 51: 249-253.

6. Caughey AB, Stotland NE, Washington AE, et al. (2007) Maternal and obstetric complications of pregnancy are associated with increasing gestational age at term. Am J Obstet Gynecol 196: 155.

7. Deering SH, Carlson N, Stitely M, et al. (2004) Perineal body length and lacerations at delivery. J Reprod Med 49: 306-310.

8. Halperin O, Raz I, Ben-Gal L, et al. (2010) Prediction of perineal trauma during childbirth by assessment of striae gravidarum score. J Obstet Gynecol Neonatal Nurs 39: 292-297.

9. Carroli G, Mignini L (2009) Episiotomy for vaginal birth. Cochrane Database Syst Rev 21: cd000081.

10. Picard D, Sellier S, Houivet E, et al. (2015) Incidence and risk factors for striae gravidarum. J Am Acad Dermatol 73: 699-700.

11. Rathore SP, Gupta S, Gupta V (2011) Pattern and prevalence of physiological cutaneous changes in pregnancy: A study of 2000 antenatal women. Indian J Dermatol Venereol Leprol 77: 402.

12. Atwal GS, Manku LK, Griffiths CE, et al. (2006) Striae gravidarum in primiparae. Br J Dermatol 155: 965-969.

13. Kapadia S, Kapoor S, Parmar K, et al. (2014) Prediction of perineal tear during childbirth by assessment of striae gravidarum score. Int J Reprod Contracept Obstet Gynecol 3: 208-212.

14. Wahman AJ, Finan MA, Emerson SC (2000) Striae gravidarum as a predictor of vaginal lacerations at delivery. Southern Med J 93: 873-876.

DOI: $10.36959 / 468 / 482$ 